Tanja Kuštović

Filozofski fakultet u Zagrebu

tkustovi@ffzg.hr

iD https://orcid.org/0000-0001-5601-3183

\title{
Jezično jedinstvo i stilska razvedenost hrvatskih protestantskih tekstova 16. stoljeća
}

Sažetak: U 16. stoljeću hrvatski protestantski pisci u Urachu tiskaju tekstove glagoljicom, ćirilicom i latinicom nastojeći da njihova djela dopru do što šireg kruga čitatelja. Jedno je od tih djela i Spovid i spoznanie prave krsztianske vere koju su preveli Antun Dalmatin i Stipan Konzul 1564. godine te objavili na glagoljici i latinici. To je djelo prijevod kritičkoga izdanja Augsburške vjeroispovijesti koju je priredio Philip Melanchthon. Riječ je o nebiblijskom tekstu podijeljenom u dva dijela: u prvom je tiskan dvadeset i jedan članak ili ,,artikul“, a u drugom su tiskani duži članci o vjeri, dobrim djelima, o lošim običajima i drugo. U dosadašnjim proučavanjima hrvatskih protestantskih tekstova naglasak je uglavnom bio na Novom testamentu, a u posljednje se vrijeme proučavaju i nebiblijski protestantski tekstovi. Poznato je otprije da jezik biblijskih tekstova nije jednak jeziku nebiblijskih tekstova, tj. da biblijski tekstovi imaju znatno više hrvatsko-staroslavenskih obilježja. U ovom ću radu proučiti jezična, prije svega morfološka obilježja oblika u tekstu koji do sada nije jezično obrađivan (Spovid i spoznanie prave krsztianske vere) te ću ih usporediti s jezičnim obilježjima iz Novog testamenta. U zaključku se utvrđuje razlikuje li se jezik nebiblijskih protestantskih tekstova od jezika biblijskih tekstova koje su u istom vremenu objavili hrvatski protestanti.

Ključne riječi: protestanti, glagoli, Spovid, Novi testament

\section{Uvod}

Reformacijski pokret započinje u Europi početkom 16. stoljeća. Njegov je začetnik Martin Luther. Izraz „reformacija“ odnosi se na povijesno razdoblje od 1517. do 1618. godine. Taj je pokret rezultirao stvaranjem novog vjerskog učenja - protestantizma. Kad govorimo 
o hrvatskom prostoru, protestantizam se razvio po cijeloj Hrvatskoj, ali se jače osjetio u njenim rubnim dijelovima. ${ }^{1}$ Gledano u odnosu na Europu, „hrvatske su zemlje bile rubna područja širenja reformacije na jugoistok Europe...".2 Lutherova reformacija širi se ponajprije tiskanom knjigom. Za kulturu reformacija je važna stoga što je potakla književno stvaralaštvo na različite načine: pisci pišu knjige, knjige se prevode, tiskaju, raspačavaju, čitaju. Možemo slobodno reći da je reformacija potakla masovno opismenjivanje ljudi. ${ }^{3}$ Protestanti ističu važnost Biblije jer vjeruju „da Biblija govori jednako intelektualcima njihova vremena kao i običnim ljudima“" ${ }^{4}$ Kao svoj veliki zadatak postavljaju prijevod Biblije na narodni jezik kako bi narod mogao razumjeti ono što je zapisano. Hrvatski protestanti tiskali su svoja djela u Urachu u Njemačkoj između 1561. i 1565. godine. Za to vrijeme otisnuli su 14 naslova, od kojih su neki otisnuti svim trima hrvatskim pismima (glagoljicom, ćirilicom i latinicom), a neki jednim ili dvama hrvatskim pismima. Brojenjem je lako ustanoviti da je većina tekstova otisnuta glagoljicom. Ugrubo te tekstove možemo podijeliti na biblijske i sve ostale (nebiblijske), pri čemu u biblijske tekstove ubrajamo Prvi i Drugi del Novog testamenta otisnut glagoljicom, Novi testament otisnut ćirilicom i Starozavjetne proroke otisnute latinicom. Popis nebiblijskih tekstova za ono je vrijeme prilično velik s obzirom na probleme s kojima su se protestanti susretali, kao što je jezična neuređenost i stalne nedoumice oko toga kakav bi jezik tih tekstova trebao biti. Te su nedoumice vidljive u predgovorima knjiga koje su objavljivali. Prema Alojzu Jembrihu nebiblijski se tekstovi mogu podijeliti prema sadržaju i namjeni na pokusne listove, početnice, katekizme, dogmatsko-katehetska djela, propovijedi, teološke rasprave i liturgijske priručnike. ${ }^{5}$

U ovom radu ne nabrajam sve objavljene protestantske tekstove, ${ }^{6}$ već spominjem samo dokument na kojem se rad temelji: Spovid i spoznanie

\footnotetext{
${ }^{1}$ „Reformacija je zahvatila sve krajeve Hrvatske ali se jače osjetila i razrasla na njezinim rubnim dijelovima. U hrvatskoj se znanosti taj pokret naziva protestantizmom; ,protestanti ${ }^{6}$ sebe vole nazivati evanglicima, a naš ih je narod zvao luteranima, pa i onda kad su oni pripadali drugim strujama u okviru protestantskog pokreta (npr. flacijanisti, kalvini)“ (Josip Bratulić, Hrvatski protestantski pisci (Vinkovci: Riječ, 2006), 6).

${ }^{2}$ Stanko Jambrek, Reformacija nekad i danas (Zagreb: Biblijski institut, 2017), 8.

${ }^{3}$ Jambrek, Reformacija nekad i danas, 7.

${ }_{4}^{4}$ Jambrek, Reformacija nekad $i$ danas, 37.

${ }^{5}$ Alojz Jembrih, „Od uspjeha do izjave ,viel falsch` o uraškom glagoljskom Novom zavjetu (1562/63),“ Prilozi za istraživanje hrvatske filozofske baštine, sv. 32, br. 1-2 (2006): 38.

${ }^{6}$ Radove su popisali i s osnovnim podacima opisali Franjo Bučar i Franjo Fancev 1938. godine. Franjo Bučar i Franjo Fancev, „Bibliografija hrvatske protestantske književnosti za reformacije,“ Starine JAZU, br. 39 (1938): 49-128.
} 
prave krsztianske vere. Djelo su preveli Antun Dalmatin i Stipan Konzul 1564. godine te ga iste te godine objavili i na glagoljici i na latinici. To je djelo kritički prijevod izdanja Augsburške vjeroispovijesti koju je priredio Philip Melanchthon. Tekst je, kao što stoji u samom uvodu, preveden s latinskog i njemačkog jezika. Izdavači se čitatelju obraćaju u dva navrata: na samom početku i na samom završetku. Na početku objašnjavaju razlog izdavanja tog teksta: „I tako štampano jest', da va mnozih' mestih' se nahodi hoteći jest' skvareno" (Spovid 1564: 2). U obraćanju čitatelju na kraju teksta izdavači podsjećaju da je Spovid već otisnuta (misli se na tekst Artikula), ali s opširnim tumačenjima da bi bila što razumljivija običnim čitateljima: „Pred' malim' vrimenom', jest' ova Avgustanska Spovid' S hrvatckimi i S ciruliskimi slovmi štampana: Ali veće z dlgim' i obilneim' tlmačen'jem', zato da bi priprosti ljudi tu istu bolê mogli razumeti“ (Spovid 1564: 113v), a ova knjiga koja je sada objavljena (Spovid) objavljena je onako kako ju je primio pokojni rimski car Karlo V: „Tako jesmo ovu sad(a)šnju Knjigu, prez niednoga prilagan'ja, čisto i verno iz Diačkoga jazika, od' beside do beside istlmačili: Onako kako jest' pokoinomu Rimskomu Cesaru Karolu petomu (...) u godišću 1530. Va Avgusti izručena..." (Spovid 1564: 113v).

Riječ je o nebiblijskom tekstu podijeljenom u dva dijela: u prvom je tiskan dvadeset i jedan članak ili ,artikul“, a u drugom su tiskani duži članci o vjeri, dobrim djelima, o lošim običajima, o zakonu i ženidbi svećenika i drugo.

Dosadašnja proučavanja hrvatskih protestantskih tekstova stavljala su naglasak na Novi testament, a tek u posljednje vrijeme proučavaju se u većem opsegu i nebiblijski protestantski tekstovi. Poznato je otprije da jezik biblijskih tekstova (ne ovih protestantskih) nije jednak jeziku nebiblijskih tekstova, tj. da biblijski tekstovi imaju znatno više hrvatsko-staroslavenskih obilježja od nebiblijskih tekstova, u kojima su dominantna hrvatska obilježja. Ovdje ću nastojati istražiti je li takva situacija u hrvatskim protestantskim tekstovima, tj. razlikuje li se jezik protestantskih biblijskih tekstova od jezika protestantskih nebiblijskih tekstova. ${ }^{8}$

\footnotetext{
${ }^{7}$ Tekst je transliteriran u okviru projekta Jezik izdanja hrvatske protestantske tiskare u kontekstu književnojezičnih smjernica XVI. st. koji financira Hrvatska zaklada za znanost, pod vodstvom prof. Matea Žagara i čeka svoju objavu.

${ }^{8}$ Ovdje treba napomenuti da je autorica ovoga rada u suautorstvu s Verom Blažević Krezić napravila i usporedbu nebiblijske Postile s tekstom Novog testamenta; Vera Blažević Krezić i Tanja Kuštović, „Usporedba jezika homilija i novozavjetnih tekstova u glagoljičkoj, ćiriličkoj i latiničkoj Postili“ (2021). U tisku.
} 
Uspoređujući jezik glagoljaša 16. stoljeća s jezikom protestanata iz istog vremena, Stjepan Damjanović utvrđuje da su protestanti htjeli isti jezik kakav su htjeli i glagoljaši: pretežito čakavsko-staroslavenski, samo s manjim brojem staroslavenskih elemenata, pri čemu te staroslavenske elemente ipak nisu sveli samo na simboliku. ${ }^{9}$ Protestantska je Spovid dokument koji je u obzor detaljnijeg proučavanja dospio zahvaljujući projektu Jezik izdanja hrvatske protestantske tiskare u kontekstu književnojezičnih smjernica XVI. stoljeća koji financira Hrvatska zaklada za znanost, pod vodstvom prof. Matea Žagara. Uz njega na projektu sudjeluju: akademik Stjepan Damjanović, Blanka Ceković, Ivana Eterović, Vera Blažević Krezić i Tanja Kuštović. U radu „Grafetička i grafematička obilježja protestantske Spovidi (1564) u kontekstu hrvatskoga književnog jezika 16. stoljeća"10 Vera Blažević Krezić obradila je navedena obilježja Spovidi, a u ovom će se radu na primjeru glagola nastojati pokazati kako izgleda njihov morfološki opis u odnosu na isti opis glagola u protestantskom glagoljskom Novom testamentu (1562/1563). Ti će se rezultati usporediti s jezičnim obilježjima hrvatskih tekstova iz 16. stoljeća koje nisu objavili hrvatski protestanti. Budući da je riječ o tekstovima različite namjene (biblijskom i nebiblijskom tekstu), nije bilo moguće pronaći paralelne tekstove, pa je istraživanje provedeno na tekstu Muke po Mateju iz Novog testamenta (NT 1r-45v) ${ }^{11}$ i na tekstu Spovidi (S 59v-65v). Rezultati se uspoređuju s istraživanjima čakavskih tekstova iz 16. stoljeća koja su proveli Boris i Martina Kuzmić i objavili ih u knjizi Povijesna morfologija hrvatskoga jezika. ${ }^{12}$

Analiza se provodi na glagolskim oblicima s namjerom da se utvrdi koliko staroslavenskih elemenata možemo pronaći u Novom testamentu i Spovidi, je li njihov broj zanemariv, jesu li ti elementi konstantni za pojedini glagolski oblik i glagolsko lice ili možemo govoriti o povremenim pojavljivanjima.

\footnotetext{
9 Tanja Kuštović, „Filološka proučavanja hrvatskih protestantskih tekstova,“ u Meandrima hrvatskoga glagoljaštva. Zbornik posvećen akademiku Stjepanu Damjanoviću o 70. rođendanu, ur. Tanja Kuštović i Mateo Žagar (Zagreb: Hrvatska sveučilišna naklada, 2016), 245.

${ }^{10}$ Vera Blažević Krezić, „Grafetička i grafematička obilježja protestantske Spovidi (1564) u kontekstu hrvatskoga književnog jezika 16. stoljeća,“ Fluminensia, sv. 31, br. 2 (2019): 49-86.

${ }^{11}$ Za pomoć pri analizi Novog testamenta korišten je program osmišljen za proučavanje jezika Novog testamenta koji se nalazi na poveznici https://jt195996.pythonanywhere.com/ NT1561/default/index.

${ }^{12}$ Boris Kuzmić i Martina Kuzmić, Povijesna morfologija hrvatskoga jezika (Zagreb: Hrvatska sveučilišna naklada), 2015.
} 


\section{Analiza glagola}

\subsection{Prezent}

Ako pogledamo prezent u Novom testamentu, vidimo da u prvom licu jednine nalazimo stariji završetak - $u$ : govoru (ja stanovito govoru vam 3B), zataju (ne zataju tebe 40A), ${ }^{13}$ reku (i reku ovomu poidi i poidet 10A), piju (ako li ne more minuti Čaša ova od mene, nego da ju piju 40B) i noviji završetak -m: celuem (Koga godi ja celuem 40B), zaklinam (Zaklinam te živim Bogom 41B). Iste nastavke nalazimo i u Spovidi: govoru (A ne govoru tebi 63a), mogu (ne mogu prez' griha 67a), zapovidam' (suprot zapovidam' 67b), govorim (ne govorim 67b). U Spovidi nalazimo različite nastavke za isti glagol govoriti. Treba reći da i Novi testament $\mathrm{u}$ nekim drugim dijelovima ima za istu riječ oba oblika (po prilikah im govorim 18A), a što se tiče učestalosti, češći je oblik govoru. I u Spovidi nastavak - $u$ češći je od nastavka $-m$ pa možemo reći da se u oba teksta, biblijskom i nebiblijskom nastavak - $m$ javlja sporadično, ali da ga unatoč tomu ne možemo zanemariti. Franjo Fancev utvrdio je da završetak - $u$ nije uvijek bio odjek živoga govora, već i jakoga utjecaja crkvenoga jezika. ${ }^{14}$ Gledajući ukupnost tekstova 16 . stoljeća, nastavak $-u$ za prvo lice jednine prezenta obilježje je i svih razdoblja čakavskog hrvatskog književnog jezika ${ }^{15}$ i štokavskog hrvatskog književnog jezika ${ }^{16}$ pa ne možemo govoriti o obilježju preuzetom iz hrvatskocrkvenoslavenskog, već o obilježju koje je zajedničko i hrvatskocrkvenoslavenskom, i čakavskom, i štokavskom književnom jeziku. ${ }^{17}$ Zapravo bismo mogli reći da je nastavku $-u$ pogodovala činjenica da je on rezultat fonološke promjene $(\mathrm{Q}>\mathrm{u}) \mathrm{i}$ istovremeno odjek živoga govora.

U drugom licu jedine staroslavenski nastavak -ši uopće ne nalazimo u jeziku proučavanih tekstova. Upotrebljava se hrvatski nastavak $-\check{s}$ i u Novom testamentu (ti kad moliš 7A, moreš mene ozdraviti 10A) i u Spovidi (moreš' milost' dobiti 63a, da je pomrsiš 63b). Starog nastavka nije bilo ni u hrvatskim tekstovima 16. stoljeća.

\footnotetext{
${ }^{13}$ Značenje je futursko, ali oblik je prezentski.

${ }^{14}$ Franjo Fancev, ,Jezik hrvatskih protestantskih pisaca 16. vijeka: Prilog historičkoj gramatici jezika hrvatskoga ili srpskoga,“ Rad JAZU, br. 214 (1916b): 115.

${ }^{15}$ Kuzmić i Kuzmić, Povijesna morfologija hrvatskoga jezika, 45.

${ }^{16}$ Kuzmić i Kuzmić, Povijesna morfologija hrvatskoga jezika, 86-87.

${ }_{17}$ Tanja Kuštović i Mateo Žagar, „Jezične usporednice u Muci po Mateju u glagoljskom Novom testamentu (1562.) i u kodeksima Bartola Krbavca," u Muka kao nepresušno nadahnuće kulture - Pasionska baština Like, Zbornik radova 12. međunarodnog znanstvenog simpozija održanog u Gospiću i Ličkom Osiku 7.-10. lipnja 2018., ur. Jozo Čikeš (Zagreb: Udruga Pasionska baština, 2019), 172-229.
} 
U trećem licu jednine prezenta nastavak - $t$ dolazi u Novom testamentu samo sporadično: budet (i budet čistiti 3B), padet (ne padet na zemlju 14A), a prevladavaju nastavci $-a,-e,-i-$ ovisno o osnovi glagola: se proliva (ka se proliva za mnozih 40A), zapoe (Prvo nego peteh zapoe 42A), pristoi se (Ne pristoi se stavit ih 42A), moli (moli ga govoreći 26B). Iste nastavke nalazimo i u Spovidi: zapovida (ka zapovida 60a), more (lahko se more razumiti 62b), govori (Kristus' govori 65b). Dakle, bez nastavka $-t$.

U trećem licu množine prezenta situacija je ista kao i u jednini: Novi testament ima samo pojedinačne slučajeve s nastavkom -t: rastekut (i rastekut se ovce stada 40A), a prevladavaju oblici bez tog nastavka: uhite, ubiju (da isusa hinbeno uhite i ubiju 39A). ${ }^{18} \mathrm{U}$ Spovidi nastavka - $t \mathrm{u}$ tom licu uopće nema: propinjaju, mис̆e (Potom' propinjaju i mис̆e 60a), zapovidaju (brže zapovidaju 60a).

Kad govorimo o prezentu, spomenimo i glagol htjeti koji u trećem licu množine glasi hote i u Novom testamentu (jere hote Boga viditi 5A) i u Spovidi (človičaske naredbe hote 66b). S druge strane oblik hoće rezerviran je i u biblijskim i u nebiblijskim tekstovima za treće lice jednine: on hoće izdati mene (NT 39B), Paval' hoće da se ugibamo (S 67b). Možemo pretpostaviti da se oblikom hote htjelo izbjeći podudaranje s oblikom za treće lice jednine ${ }^{19} \mathrm{i}$ to se provodilo u svim tekstovima, bez obzira na to jesu li biblijski ili nisu. Dodajmo da se oblik hote pojavljuje u čakavskom, kajkavskom, štokavskom te u tronarječnom (hibridnom) hrvatskom književnom jeziku u 16. stoljeću. ${ }^{20}$

Prvo lice množine s nastavkom -mo nalazimo u oba proučavana teksta, kao i u drugim tekstovima iz 16. stoljeća: preselimo (NT dopusti nam da se preselimo 11A), učimo (S tako učimo 69b). U oba slučaja riječ je o hrvatskim oblicima. Nema posebnosti ni u nastavku -te koji je zajednički i staroslavenskom i hrvatskom jeziku (NT izvana se vidite ljudem pravadni 34B, S zašto tako živući na svitu postave činite 71a).

\footnotetext{
${ }^{18} \mathrm{O}$ nastavku za treće lice množine u Novom testamentu vidi Kuštović i Žagar, „Jezične usporednice u Muci po Mateju u glagoljskom Novom testamentu (1562.) i u kodeksima Bartola Krbavca,"186-187.

${ }^{19}$ Isto je stanje potvrđeno i u protestantskom izdanju Artikula. Vidi: Tanja Kuštović, „Glagolski oblici u protestantskom izdanju Artikuli ili deli prave stare krstianske vere (1562.),“ Slovo, br. 67 (2017): 99.

${ }^{20}$ Kuzmić i Kuzmić, Povijesna morfologija hrvatskoga jezika, 45, 87, 120, 153.
} 


\subsection{Imperativ}

Imperativ kao zapovjedni način izražen je u drugom licu jednine nastavkom -i u oba dokumenta: ne kradi, ne govori, ne čini (NT 28A); Očitui Gospodinu put' tvoi (S 63a), grihe tvoe izruči (S 63a). Osim toga u Spovidi u drugom licu jednine nalazimo primjere spovei grihe tvoe spovei (63a) i povei je vsaki dan v' duši tvoioi (63b). Fancev to naziva neobičnim oblikom. ${ }^{21}$ Nastavak $-i$ imamo i u trećem licu jednine u Novom testamentu: budi vola tvoja (40B), Krv njegova budi zvrhu nas (43A) i u Spovidi: što godire vnide va usta, ne oskvrni i ne opogani človika (71a). Uz to u oba dokumenta imamo za treće lice jednine i tvorbu pomoću čestice neka i prezenta glagola: neka on oslobodi njega (NT 43B), neka vas' niedan ne sudi (S 70b). I treće lice množine i u Novom testamentu i u Spovidi tvoreno je česticom neka i prezentom glagola: neka mrtvi pokopaju mrtve svoe (NT 10B); neka razumiju (S 60b). Zanimljivo je i to da je prvo lice množine izraženo oblikom neka + prezent u oba dokumenta: neka učinimo ovdi tri krovi (NT 24B); Neka učimo broenie grihov' (S 62a). Za izražavanje imperativa prvog lica množine rabi se i uobičajeni oblik prezenta: Evo, ushodimo v jerusolim (NT 29A). Čestica $d a$ koja je bila u staroslavenskom čestica kojom se mogao tvoriti imperativ u trećem licu jednine i množine u Spovidi se ne javlja, ali se javlja u Novom testamentu u trećem licu jednine u kombinaciji s prezentom: da ne bude (NT 36A, 39A). Stanje u čakavskom književnom jeziku 16. stoljeća takvo je da se za izražavanje trećeg lica jednine upotrebljava analitički imperativ tvoren pomoću čestica da i neka + prezent, a prvo i drugo lice množine izražavaju se nastavcima -imo, -ite. ${ }^{22}$ Kuzmić i Kuzmić spominju i tvorbu pomoću starog imperativa glagola moći i infinitiva: ne mozi već dati. ${ }^{23}$ Taj oblik tvorbe u našim protestantskim tekstovima ne nalazimo.

Prošlost se izražava jednostavnim i složenim glagolskim vremenima: aoristom, imperfektom, perfektom i pluskvamperfektom.

\subsection{Aorist}

Za aorist imamo u Novom testamentu mnoštvo primjera za različita lica. Za prvo lice jednine: pridoh, rekoh, donesoh (ne pridoh 11B, ne

\footnotetext{
${ }^{21}$ Fancev navodi posebne oblike imperativa u Spovidi: pred' Bogom' grihe tvoe spovei (S) grihe tvoe povei (S); Fancev, ,Jezik hrvatskih protestantskih pisaca 16. vijeka: Prilog historičkoj gramatici jezika hrvatskoga ili srpskoga,“ 130.

${ }^{22}$ Kuzmić i Kuzmić, Povijesna morfologija hrvatskoga jezika, 47.

${ }^{23}$ Kuzmić i Kuzmić, Povijesna morfologija hrvatskoga jezika, 47.
} 
rekoh 12B, tere ga donesoh 25A), za treće lice jednine: pristupi, pade, pride, naide i dr. (tada pristupi $\mathrm{k}$ Isusu 21B, Niko opet pade meju trnje 18A, I kada pride naide ju 17B), za prvo lice množine: vidismo, učinismo (jere vidismo zvizdu negovu 2A, mnoge kriposti učinismo 9B), za drugo lice množine: prijeste, izidoste, hotiste, razumiste (zaostunj prijeste 13A, izidoste u pustinju 14B, hotiste plakati 15A, razumiste li sva ova 19B), za treće lice množine: pridoše, privedoše, rekoše (pridoše u grad 11A, privedoše k njemu drhtavca 11A, učenici rekoše nemu 18A) samo su neki od njih. Ako pogledamo odnos svršenih i nesvršenih glagola u Novom testamentu, možemo reći da se aorist tvorio i od jednih i od drugih. Za razliku od tog prilično čestog vremena za izražavanje prošlosti u Novom testamentu, u Spovidi na proučenom tekstu nalazimo samo vnide i aorist glagola biti izražen oblicima: bi, bê (bi potribno 64a, tako bê posut 60b). Za tekstove iz 16. stoljeća Kuzmić i Kuzmić zaključuju da se aorist češće tvorio od svršenih glagola, ali da postoji i tvorba od nesvršenih glagola. ${ }^{24}$

\subsection{Imperfekt}

Imperfekt je češći oblik od aorista u Spovidi, što se može objasniti činjenicom da se za izražavanje potrebnih značenja rabe nesvršeni glagoli. Primjere za imperfekt nalazimo u trećem licu jednine: mnjaše, hranjaše, rejaše, rojaše, vladaše (Krstijanstvo se mnjaše 67b, Da otac' od' obiteli hranjaše dicu i čelad' rejaše. Da mati rojaše. Da poglavnik' vladaše obćenu varošku rič 68a) i u trećem licu množine: mnjahu, bihu, učahu, izbirahu, imijahu i dr. (začto se mnjahu da ona dela bihu vridna 67a, ki učahu 61b, izbirahu se Ceremonie 64a, ni čast' ne imijahu 68a). Imperfekt nalazimo i u Novom testamentu u trećem licu množine: marahu (A oni ne marahu 32A), ali ne i u trećem licu jednine. Zanimljiv je primjer: koi dohodak prijimlahu, i rekoše (25A) u kojem je svršeni oblik glagola stavljen u aorist (rekoše), a nesvršeni u imperfekt (prijimlahu) premda se nalaze neposredno jedan do drugoga. Prevoditelj teksta iskoristio je stilističku, ali i gramatički opravdanu, mogućnost variranja različitih glagolskih oblika u neposrednom susjedstvu. I u tekstovima iz 16. stoljeća imperfekt se rijetko tvori od nesvršenih glagola. ${ }^{25}$

\footnotetext{
${ }^{24}$ Kuzmić i Kuzmić, Povijesna morfologija hrvatskoga jezika, 45.
}

${ }^{25}$ Kuzmić i Kuzmić, Povijesna morfologija hrvatskoga jezika, 45. 


\subsection{Perfekt}

Perfekt se tvori od trajnog prezenta pomoćnog glagola biti i l-participa. Ono što je u Spovidi bitno drugačije od Novog testamenta kad je riječ o glagolima upravo je upotreba perfekta. Naime, perfekt se znatno češće upotrebljava u Spovidi nego u Novom testamentu. No, ne možemo reći da perfekta u Novom testamentu nema. Usporedba s hrvatskocrkvenoslavenskim tekstom Berlinskog misala iz 1402. godine pokazala je da se u Novom testamentu češće upotrebljava perfekt od aorista: ${ }^{26}$ učinila jest (jere dobro dilo učinila je(st) u mni 43A), si rekal (Ti si rekal 41B), jest rekal (jest on lastac rekal 44B). Na tim mjestima u Berlinskom misalu nalazimo aorist. Ako pogledamo broj primjera perfekta u Spovidi, vidjet ćemo da to glagolsko vrijeme preteže kad treba iskazati prošlost: jesu očitovali i prosvitili (60b), su se učili (66b), bezufali jesu (68b). Vidljivo je da je u oba teksta prisutna tvorba i s naglašenim i s nenaglašenim oblikom prezenta glagola biti, a to je u skladu i s tekstovima iz 16. stoljeća.

\subsection{Pluskvamperfekt}

Pluskvamperfekt se u Spovidi tvori na jedan način - imperfektom glagola biti i l-participom: bihu slišali (od pravice vire ne bihu slišali 68b), bihu prestupili (brani ki bihu prestupili 71a), a tako je i u Novom testamentu: koe bihu naslidovale Isusa (44A). Hrvatski tekstovi iz 16. stoljeća tvore pluskvamperfekt od imperfekta ili perfekta pomoćnog glagola biti i $l$-participa. Imaju ga svršeni i rjeđe nesvršeni glagoli. ${ }^{27}$

\subsection{Izražavanje budućnosti}

Budućnost se u analiziranom tekstu izražava futurom I. Za tvorbu je služio u Spovidi prezent pomoćnog glagola htjeti (i to isključivo naglašeni oblik prezenta) $\mathrm{i}$ infinitiv glagola: zdati hote (i hvalu zdati hote 65b), hoće oslabiti (da se hoće oslabiti 74a). U Novom testamentu uz pomoćni glagol htjeti upotrebljava se i pomoćni glagol biti: I budeš imenovati ime njegovo Isus (1B), Irud bude iskati Ditića (2B), budete blagovati $i$ piti (8A), hoćemo piti (8B), hote se skupiti (36A), hoću uskrsnuti (44B). U Novom testamentu budućnost se izriče i futurom II. koji se tvori od nesvršenog oblika prezenta glagola biti i l-participa:

\footnotetext{
${ }^{26}$ Kuštović i Žagar, „Jezične usporednice u Muci po Mateju u glagoljskom Novom testamentu (1562.) i u kodeksima Bartola Krbavca," 188.

${ }^{27}$ Kuzmić i Kuzmić, Povijesna morfologija hrvatskoga jezika, 46.
} 
tada se budu postili (12A), ko budu govorili ljudi (17A), Zvizde budu padale z neba (36A). U hrvatskim tekstovima iz 16. stoljeća budućnost se izražavala i futurom I. i futurom II. koje su imali i svršeni i nesvršeni glagoli.

\subsection{Participi}

U Novom testamentu kao i u Spovidi ne nalazimo participe kao u starijim misalskim tekstovima. Oni su zamijenjeni glagolskim prilozima ili zavisnom rečenicom, čime je omogućena veća razumljivost tekstova. Glagolski prilog sadašnji potvrđuju primjeri u Novom testamentu: govoreći (upita Učenike svojee, govoreći 23B), blagujući (i blagujući reče 39B), glaseći se, zvoneći (kako glasu iz' neba glaseći se ili zvoneći 61b). Međutim, ne možemo reći da aktivnog participa prezenta uopće nema. Iz nekoliko primjera vidimo da se on sklanjao kao pridjev po određenoj deklinaciji: vi ne greste unutar i prihodećim ne daste ulisti (34A), grišniku pokoru činećega (65b). Aktivni particip preterita I. i u Novom testamentu i u Spovidi više se ne deklinira, pa govorimo o glagolskom prilogu prošlom: I ostavivši množtvo, uzaide na goru (NT 21A), ukorenivši se (S 64b A oni stari običaii su se posedili i postarali ukorenivši se). Novi testament ima i stariji oblik koji se deklinira: i kad ga svukoše, ogarnuvše ga plašćem črvlenim (43A). Takvog oblika nema u tekstu Spovidi. Čakavski tekstovi iz 16. stoljeća u skladu su $\mathrm{s}$ navedenim primjerima u protestantskim tekstovima, s tim što imaju i starije oblike koje u protestantskim tekstovima ne nalazimo: grede, hode. Stariji oblici sačuvani su u 16. stoljeću i u aktivnom participu preterita I. ${ }^{28}$

\section{Zaključak}

Ako bismo kao jedini kriterij razlikovnosti uzeli glagole u biblijskom i nebiblijskom dokumentu koje su za tisak jezično priredili hrvatski protestanti, mogli bismo reći da morfološki nema velikih razlika između proučavanih tekstova. U prezentu u trećem licu jednine i množine Novi testament ima uz češći nastavak $-e,-a,-i$ i nastavak $-t$, koji ne nalazimo u Spovidi. Imperativ u Novom testamentu u trećem licu jednine tvoren je česticom $d a+$ prezent. Istu česticu ne nalazimo u Spovidi. Tu nalazimo samo česticu neka, koja postoji i u Novom testa-

${ }^{28}$ Kuzmić i Kuzmić, Povijesna morfologija hrvatskoga jezika, 48. 
mentu. Što se tiče izražavanja prošlosti u tim dokumentima, vidimo da je u Novom testamentu češća upotreba jednostavnih glagolskih vremena (aorista i imperfekta), dok je u Spovidi češće u upotrebi perfekt. Takvo nas stanje ne čudi s obzirom na to da je upotreba aorista i imperfekta karakteristična za biblijski stil, i nekad i danas. Ivo Pranjković tu pojavu naziva biblizmom. ${ }^{29} \mathrm{U}$ tvorbi futura I. u Novom testamentu rabe se dva pomoćna glagola: biti i htjeti s infinitivom, za razliku od Spovidi u kojoj je jedini pomoćni glagol - glagol htjeti.

Ako sudimo samo na temelju glagola, možemo reći da su protestanti znatno pomladili jezik tekstova u odnosu na tekstove iz starijih razdoblja te ga tako učinili razumljivijim narodu, bez obzira na to je li riječ o biblijskim ili nebiblijskim tekstovima. Analiza drugih sastavnica (npr. zamjenica) možda bi mogla dati nešto drugačiju sliku o jeziku protestantskih tekstova.

\section{Literatura}

Blažević Krezić, Vera. „Grafetička i grafematička obilježja protestantske Spovidi (1564) u kontekstu hrvatskoga književnog jezika 16. stoljeća.“ Fluminensia, sv. 31, br. 2 (2019): 49-86.

Blažević Krezić, Vera, i Tanja Kuštović. „Usporedba jezika homilija i novozavjetnih tekstova u glagoljičkoj, ćiriličkoj i latiničkoj Postili.“ (2021). U tisku.

Bratulić, Josip. Hrvatski protestantski pisci. Vinkovci: Riječ, 2006.

Bučar, Franjo, i Franjo Fancev. „Bibliografija hrvatske protestantske književnosti za reformacije.“ Starine JAZU, br. 39 (1938): 49-128.

Damjanović, Stjepan. „Jezik glagoljičnih tekstova šesnaestoga stoljeća.“ U Povijest hrvatskoga jezika od srednjega vijeka do XXI. stoljeća. 2. knjiga: 16. stoljeće, uredio Ante Bičanić, 11-22. Zagreb: Croatica, 2011.

Fancev, Franjo. „Jezik hrvatskih protestantskih pisaca 16. vijeka: Prilog historičkoj gramatici jezika hrvatskoga ili srpskoga.“ Rad JAZU, br. 212 (1916a): 147-225.

Fancev, Franjo. „Jezik hrvatskih protestantskih pisaca 16. vijeka: Prilog historičkoj gramatici jezika hrvatskoga ili srpskoga.“ Rad JAZU, br. 214 (1916b): 1-112.

Jambrek, Stanko. Reformacija nekad $i$ danas. Zagreb: Biblijski institut, 2017.

Jembrih, Alojz. „Od uspjeha do izjave ,viel falsch“ o uraškom glagoljskom Novom zavjetu (1562/63).“ Prilozi za istraživanje hrvatske filozofske baštine, sv. 32, br. 1-2 (2006): 35-67.

Kuštović, Tanja. „Filološka proučavanja hrvatskih protestantskih tekstova.“ U Meandrima hrvatskoga glagoljaštva. Zbornik posvećen akademiku Stjepanu Damjanoviću o 70. rođendanu, uredili Tanja Kuštović i Mateo Žagar, 237-250. Zagreb: Hrvatska sveučilišna naklada, 2016.

\footnotetext{
${ }^{29}$ Ivo Pranjković, „Hrvatski jezik i biblijski stil,“ u Zbornik radova 34. seminara Zagre-
} bačke slavističke škole, ur. Krešimir Bagić (Zagreb: FF Press, 2006), 23. 
Kuštović, Tanja. „Glagolski oblici u protestantskom izdanju Artikuli ili deli prave stare krstianske vere (1562.).“ Slovo, br. 67 (2017): 91-112.

Kuštović, Tanja, i Mateo Žagar. „Jezične usporednice u Muci po Mateju u glagoljskom Novom testamentu (1562.) i u kodeksima Bartola Krbavca."U Muka kao nepresušno nadahnuće kulture - Pasionska baština Like, Zbornik radova 12. međunarodnog znanstvenog simpozija održanog u Gospiću i Ličkom Osiku 7.-10. lipnja 2018., uredio Jozo Čikeš, 172-229. Zagreb: Udruga Pasionska baština, 2019.

Kuzmić, Boris, i Martina Kuzmić. Povijesna morfologija hrvatskoga jezika. Zagreb: Hrvatska sveučilišna naklada, 2015.

Pranjković, Ivo. „Hrvatski jezik i biblijski stil.“ U Zbornik radova 34. seminara Zagrebačke slavističke škole, uredio Krešimir Bagić, 23-32. Zagreb: FF Press, 2006.

\section{Mrežni izvori}

Izdanja hrvatske protestantske tiskare XVI. stoljeća. Pristupljeno 12. prosinca 2019. https://jt195996.pythonanywhere.com/NT1561/default/index.

\section{Izvori}

Novi testament, I. dio, 1562; latinički prijepis glagoljskog izvornika. Uredio Dragutin Matak. Zagreb: Adventističko teološko visoko učilište - Filozofski fakultet Sveučilišta u Zagrebu - Školska knjiga, 2013.

Novi testament, II. dio; 1563; latinički prijepis glagoljskog izvornika. Uredio Dragutin Matak. Zagreb: Adventističko teološko visoko učilište - Filozofski fakultet Sveučilišta u Zagrebu - Školska knjiga, 2015.

Spovid i spoznanie prave krstijanske vire, Urach 1564., uredio Mateo Žagar. Zagreb: Hrvatska sveučilišna naklada - Adventističko teološko visoko učilište, 2020.

\section{Popis kratica}

NT - Novi testament

$\mathrm{S}$ - Spovid i spoznanie prave krsztianske vere

\section{Linguistic Unity and Stylistic Diversity of the $16^{\text {th }}$ Century Croatian Protestant Texts}

Summary: In the $16^{\text {th }}$ century, the Croatian Protestant authors at Urach printed the texts in Glagolitic, Cyrillic and Latin script, in an effort to reach a wider audience. One of those texts is Spovid i spoznanie prave krsztianske vere, translated in 1564 by Antun Dalmatin and Stipan Konzul, and published in Glagolitic and Latin script. That literary work is the translation of the critical edition of The Augsburg Confession written by Philipp Melanchthon. It is a non-liturgical text divided into two parts: the first part contains 21 printed articles or ,artikul“ and the second one consists of longer articles on religion, good deeds, bad habits, etc. The previous research of Croatian Protestant texts was principally centred on the study 
of the New Testament, while only recently have non-liturgical Protestant texts come under scientific scrutiny. It has already been known that the languages of liturgical and non-liturgical texts differ, the former having considerably more Old Church Slavonic features. In this paper I am going to study linguistic, primarily morphological features in the text not previously linguistically processed (Spovid $i$ spoznanie prave krsztianske vere), and compare them to the New Testament linguistic features. The findings will help me establish the extent of variety between the language of non-liturgical and liturgical Protestant texts published by Croatian Protestants in the same period.

Keywords: Protestants, verbs, Spovid, the New Testament 